\title{
Sociodrama as a Creative Learning Strategy in Business Administration
}

\author{
Marcos Bidart-Novaes, Janette Brunstein, Antonio Carlos Gil, Joceli Drummond \\ Programa de Pós-Graduação em Administração, Universidade Presbiteriana Mackenzie, São Paulo, Brazil \\ Email: bidart@uol.com.br
}

Received 27 June 2014; revised 30 July 2014; accepted 11 August 2014

Copyright $(2014$ by authors and Scientific Research Publishing Inc.

This work is licensed under the Creative Commons Attribution International License (CC BY). http://creativecommons.org/licenses/by/4.0/

(c) (;) Open Access

\begin{abstract}
Sociodrama is a learning process focused on solutions for human relationship problems. It offers the opportunity for groups to clarify values and review behaviors, practicing new spontaneous and creative attitudes. The objective of this work is to analyze and discuss how sociodrama can be used as a methodological strategy for cooperative education in business administration. More specifically, to show how sociodramatic sessions can be used in different organizational contexts and to discuss how sociodramatic interventions foster creativity and change in the learning process between the main facilitator and other actors involved. To reach those objectives, three experiences are presented in the paper. The situations here presented show that the same technique, used with different groups, is a creative way to intervene and work with groups. It can serve critical thinking and group bonding, can foster motivation or help a group clarify values and define priorities.
\end{abstract}

\section{Keywords}

Sociodrama, Learning Strategy, Creativity

\section{Introduction}

Sociodrama is a learning process focused on solutions for human relationship problems (Sternberg \& Garcia, 2000). It also offers the opportunity for groups to clarify values and review behaviors, practicing new spontaneous and creative attitudes. Normally, what is known as a sociodramatic session is made up of non-specific or specific warm-ups, enactment and sharing. The enactment doesn't need to be accomplished in theater form, it can be done through different techniques such as games, experiences, joint composition of artworks, songs etc. Creativity is the key word here.

Moreno (1997) says that "[...] especially in the human sphere, it is impossible to understand the social present 
if we do not try to change it.” (p. 58). This phrase from Moreno, the man who launched the foundations for psychodrama and all socionomic methodology and, therefore, for sociodrama, should be sufficient to place him as one of the thinkers who form the epistemological and methodological base for action-research and other modalities of participatory, collaborative and interventionist education.

The objective of this work is to analyze and discuss how sociodrama can be used as a methodological strategy for cooperative education in business administration. More specifically, to show how sociodramatic sessions can be used in different organizational contexts and to discuss how sociodramatic interventions foster creativity and change in the learning process between the main facilitator and other actors involved. To reach those objectives, three experiences are analyzed here. 1) How sociodramatic sessions were used to open and maintain the communicative and learning space with a group of low-income women embroiderers in a cooperative under construction; 2) How sociodramatic techniques were used to raise expectations and align the conducts of a group of recently-employed civil servants on an operational level and; 3) How sociodramatic sessions were used within the scope of behavioral skills assessment and training with a group of technicians at a petrochemical plant.

The significance of this paper lies in the fat that sociodrama has been used mainly as a targeted intervention, not necessarily with a learning character. The information obtained is not always used in future interventions. However, it has been progressively revealing itself as an important tool for opening communicative spaces, for improving learning processes and for fostering conflict resolution in groups. This work is also justified by the fact that it can help eliminate the confusion, which the authors found in the reviewed literature, between sociodrama and organizational theatre. Sociodrama does not always involve enactments and theatrical scenes. Theatre in organizations does not always adhere to the sociodramatic model advocated by the followers of the tradition.

Organizational actors from areas such as health, education, administration and human resources management, who have been seeking in action-research and participatory research and education humanizing strategies focused on social transformation, could therefore benefit from knowledge of the sociodramatic method and techniques. The use of sociodrama as a learning strategy in the organizational field may benefit many parties in academia, allowing for a reflective and constructive dialogue between different areas of knowledge.

The paper presents some theoretical reflections on sociodrama and continues with the introduction of three learning interventions using Sociodrama. After that findings are analyzed and conclusions are drawn.

\section{Theoretical Reflections}

Creativity and spontaneity were nuclear aspects in Moreno's work. To talk about spontaneity and creativity in the scope of sociodrama requires some prior definitions to prevent them from being confused, for example, with naturalness, originality or innovation. Spontaneity in Moreno's sense is the capacity to act appropriately when faced with new situations, creating a new or renewing response, or the capacity to give a new response when faced with familiar situations, or one that can transform pre-established situations. It doesn't have to be spectacular or dramatic; it is unpretentious. The essential qualities of a spontaneous act are an open mind, an original approach, the will to take the initiative. It is not mere impulsivity or chance behavior; there has to be intentionality behind the creative action (Zanardini \& Di Lascio, 2004). This appropriate response is not a standardized response, but rather an integrating one for all those involved. At this point the creative potential of being is installed and in the act of creation lies the grain of humanity.

In Moreno's own words (1992) creativity-spontaneity is a propelling force of human progress, "above and independent of libido and socioeconomic motives" (p. 23). Moreno (1997) suggests that people have become used to living with organized scripts and when new situations arise they are lost before the unexpected. That is because in our culture creativity and spontaneity are far less respected than memory and intelligence.

Sociodrama is frequently confused with organizational theatre or with theatrical stagings and enactments of situations, as in Meisiek (2004). Moreno's used the master lines of socionomics and sociometrics, but also constructed new intervention possibilities with creativity (Holmes, Karp, \& Watson, 1994). There are hundreds of different sociodramatic techniques, and each could be elaborated on the way it expresses its own creative skill. According to Blatner (2005) "The various devices may be appreciated as having their own special applications. Nor are these restricted to drama maneuvers; the other creative arts are also able to be integrated” (Bp. 120).

Moreno's great search was, according to Marra (2006) for "[...] truth contextualized in action and the relational complexity of the subjects” (p. 95). Kaufmann (1992) states that it is commonly accepted that the change of attitudes and behaviors is easier achieved within a group than individually. The most important quality of a group is, according to the author, cohesion. In a united and harmonious group it is easy to communicate and to 
establish duties and rights. Sociodrama serves this purpose of building what Lewin (1970) called a solidary group, in which individuals accept the system of values and beliefs that is built or proposed.

Moreno (1997) forms his theoretical position in relation to group work by distancing himself from the ideas of Freud, who, according to Moreno (1997) considered the group to be "[...] an epiphenomenon of the individual psyche" (p. 373). He proposes that a group should be considered as a new subject, as the first step in the treatment of group questions that end up impacting the individual psyche and individual improvement.

Sociodramatic intervention conceptions are directed at transforming individuals and social systems and follow the three-phase method; warm-up, enactment and sharing. Some authors, like Blatner (2006), maintain that these three phases are preceded by a phase when the group chooses the theme to be worked on. In organizational sociodrama this only happens when the director is working in a non-consultative manner or without a pre-designed project, which is also rare in action-research works. When speaking of learning, one must also consider the importance of a fifth phase, that of processing and registering information. This processing becomes even richer when it is done from different points of view (Rodrigues, 2008). These can be the director-facilitator as a participant, the facilitator with a theoretical-technical viewpoint, the group discussing the central shared issue (Sternberg \& Garcia, 2000) or the protagonic theme (Rodrigues, 2008), or the group discussing the group dynamic and the roles represented, even when playing with games.

The purpose of the group warm-up phase is to bring the group members' attention to the here and now (Sternberg \& Garcia, 2000). It starts in an unspecific way, raising the questions, and the feelings associated with them, which mobilize the group at that moment. Then the group is gradually led to the question to be worked on, with more specific proposals directed toward that session's objective, determined by the group or by the intervener based on his previous demands.

The warm-up can be more cognitive or affective and its beginning can be dictated by the group members or the facilitator. Cognitive warm-ups provide valuable information about the way individuals think, how they construct their arguments and reasoning, and can be made through the use of readings, presentations and discussions. Affective warm-ups intend to mobilize and externalize emotions and can be aimed at strengthening relationships between participants or physically warming up the group, taking advantage of the connection between physical mobilization through dance and song, for example, and emotions. The sociodramatic director and group facilitator must be prepared and to understand what the group's needs are in terms of warm-up and if the group is accepting the proposals or not. In one way or another, the warm-ups aim to reveal perceptions and feelings that the group members have about the theme to be worked on. Also, the warm-up can be structured or unstructured. In the structured warm-up the sociodramatic director-facilitator proposes an activity that has been conceived beforehand. When it is unstructured, the facilitator defines the warm-up according to the themes and needs presented by the group when he approaches it. This allows preparation for the following phases.

The so-called scene, or dramatic games according to Yozo (1996), or simply game (Drummond \& Souza, 2008) is the next phase. In this phase the focus shifts to working on the subject that emerged from the group or that needed a resolution. It can be done in various ways, such as those exposed in Chart 1 above, with pre-conceived organizational games, films, song composition, whatever the facilitator's creativity and intuition permits. The important thing is for the scene, previously rehearsed or spontaneous, with conserved materials or materials made on the spot, serve the purpose presented in Chart 1 . That is, they must serve causal purposes, which go back to the origin of the group or organization's problems and discuss them or symptomatic purposes, directed at solving these problems and elaborating action plans. The important thing is that, through sociodrama in organizations, "[...] safeguarding the individual role and highlighting the professional, each person tries new roles, changes places with other participants and returns to his own place charged with new experiences” (Drummond \& Souza, 2008: p. 145). And these role reversals, like other psychodramatic techniques, do not have to take place on stage, in some theatrical scene that exposes people, it can come about in creative activities, in discussion, in sharing, in the understanding of presented experiences or scenes.

Rodrigues (2008), in her reference chart for group interventions, shows some aspects that influence scene elaboration in organizational sociodrama. It is important here to remember that one is not working with families, schools or communities and that the objective is not primarily therapeutic, with personal change being a possible outcome of the process. However, the work is done primarily with the aim of reaching objectives proposed by the group, by the organization or the community in the organizational sense. Thus, sociodrama can be thematic in its format or not, or it can be in the form of an axiodrama, with a theme that serves as a central axis. For this, the most varied tools can be used, such as enactment, dramatization, comedy sketches, games of chance, skill, 
competition, cooperation or theater. Intermediary objects such as drawings, puppets, sandboxes, masks, dance, music and poetry can be used. In short, creativity is again the key word. It is worth highlighting that in organizations, many of these techniques prove to be less invasive and expose the members less than dramatizations and enactments.

The use of intermediary objects (Rojas-Bermudez, 1983), merits special attention when working with organizations. With other objects (dolls, masks, tunics, hoods, images, magazine cutouts etc.) the group can carry out a gradation, increasing or decreasing the natural messages communicated with the director-facilitator team. The intermediary objects are used as a way of translating the group's emotions and thoughts. The group is encouraged in the sharing phase to talk about the objects, and what they represented.

Sharing is the final phase, which serves to unite the group in a reflection necessary to integrate what has been learned in the scene, games or experience. During this phase, scene analysis in theatrical terms is discouraged, as is judging subjects' performance when a game or experience has been carried out. The focus is on each person's expression about what he felt and learnt, stimulating acceptance of all points of views. In this sharing process individuals feel less isolated and start to realize that others have similar problems or experiences. During this phase, group members share feelings, ask questions, discuss the action and plan habit and behavior changes. "Through this process they calm down in relation to the scene, move into a cognitive scope and prepare themselves for the end of the session” (Sternberg \& Garcia, 2000: p. 20).

It is during sharing that learning is consolidated. It is at this moment of the group process that possibilities for new responses to situations that repeat themselves, or appropriate responses to new situations that arose, are discussed. For Moreno (1997), the appropriateness of the response is one of the concepts that characterize creativity and spontaneity. In organizations this is of the utmost importance, for behaviors cannot be considered creative if they are considered inadequate by the organizational culture and its groups, as people who display those behaviors are more likely to be excluded. Group transformation is a cyclical process based on agreements, dialogue, consensus and ruptures that create new needs for dialogue.

\section{The Three Experiences Analyzed}

Sociodramatic sessions in the three presented situations were conducted in the traditional manner, in a three-step continuum. They were composed of a warm-up period, the enactment and the sharing. What was common to the three cases was the composition of musical parodies. Popular music is deeply intertwined with individual and group emotion, being commonly used in gatherings and the repertoire of shared songs is usually vast in Brazil and so, one of the techniques often used by Brazilian sociodramatic directors to stimulate groups and foster creativity to compose parodies, using a well-known melody and composing lyrics for it.

The experiences presented in this work illustrate the different positions in which the facilitators find themselves and the different reflections they are forced into when, according to the cases above: 1) the intervention is ordered by the group and the facilitator voluntarily conducts it in partnership with the group; 2) the intervention is financed by the government, without its results having any impact on the job and income of the group members, as these have guaranteed job stability; 3) the intervention is carried out with employees who are in training at a company, with the facilitator working as a hired consultant and having the power to give negative opinions that may contribute to dismissals.

\subsection{The Embroiderers in the Outskirts of São Paulo}

As a first practical experience under analysis some fragments from meetings held with a group of women embroiderers, during the constitution of an entrepreneurial collective are here presented. The women embroiderers' objective was to organize themselves with collective force, in order to be able to eliminate the middlemen in the productive chain they were involved in and earn more for their work.

As a specific warm-up, a "cocktail party” was carried out during which the women were asked to talk in pairs and change partners every five minutes, following a hand-clapping sign. The suggested topic of conversation was what they thought they were doing there and what they expected from the meeting. Then the meeting went on to the scene itself. With the group sitting in a circle, each participant was asked to tell the best conversations they had had and what had interested them most in their conversation partners. In the end, as sharing, the whole group made a synthesis of the most relevant subjects, how the meeting had gone and their shared feelings.

In this meeting, the central theme was the question of how to increase the income from the embroidery work 
done at home. However, other related themes soon came up, such as obstacles put up by some of the husbands, the problem of who to leave children with and the desire for jobs and fixed incomes. In spite of the difficulty raised by time limitations, as the women at the start of this work had no more than two hours available, the "dramatic project" (Aguiar, 2006: p. 141) was slowly constructed. This goes far beyond enactments, being related to the very lives of the people involved and their community, their dreams, hopes, plans for action and the conflicts that arise during the project and that need to be confronted without manipulation by the facilitator.

Different techniques were used as a central element. Lectures given by the group members themselves were a constant, about the products they knew how to make or had made in the past, contributing to the construction of a collective identity. In one of the meetings, for example, the structure was as follows: Warm-up: When the group arrived, they were encouraged to remember who their school teachers were. They started telling stories and reminiscing. After some time we asked if the teacher that day could be one of them. They shyly said yes, "as long as it's not me”. Scene: The embroiderers' leader was invited to tell the story of how everything had started, thus taking on the teacher position, as there was a black-board behind her. She told her own embroidering story. She also talked about the number of pieces she had embroidered in the beginning and how it had all grown, scribbling this information on the black-board. She had more than half an hour at her disposal to tell the venture's whole history in rich detail. Sharing: The group was invited to sit in a circle and talk about what had made the biggest impact in this history and how their work could develop. They then raised a series of possibilities about products and markets. At the end, the group shared feelings about the meeting, with what expectations, questions, hopes and fears they were leaving it.

There were always new games, both for warming up and developing sensibilities and for main activities. As examples, we cite the use of popular or children's stories, where the women were invited to continue the stories begun with reading and interrupted at any point. These games weren't used only as a warm-up tool but rather as encouragement for subsequent sharing of thoughts, feelings and desires connected to the project. Within organizational sociodramatic theory, this is an important point: that as much as possible of what is said and brought to light be used to concretize action plans for transforming the group reality. They also serve for the director to become aware, in a playful and affectionate environment, of the subjects that most concern the group at the moment and to establish relationships with daily life and reflections about current behaviors and possible alternatives for action, which Drummond \& Souza (2008) refers to as "healthy exits".

In work of this nature, it is difficult to strictly delimit phases, both within the session and the larger cycles. For the authors of this work, three moments were decisive for establishing, with the support of sociodrama, the necessary learning space for forming the entrepreneurial collective. We decided to call them: 1) Consciousness-raising; 2) Transmission of accumulated knowledge; 3) Construction of group identity.

The moment of consciousness-raising occurred at the third meeting. There was a warm-up where the group was asked to sit in smaller groups or pairs and remember the small businesses that most drew their attention in the community. The objective of this warm-up was to make the group aware that there are countless entrepreneurs in the community, people who don't depend on formal jobs to live. They were then asked to report what had come up in the conversation and why the businesses were attractive. The scene itself was then performed. A volunteer was asked to present herself. After some embarrassment, the group jokingly "elected" a volunteer, one of the more outgoing women, as is common in this type of situation. The facilitator (scene director) asked her if she knew what she was supposed to do and she said no. She was then given an item of clothing as a gift. The women were then asked to talk about what had happened and what relationship this had with our joint work. The women themselves said that the experience had showed that for them to improve their conditions they had to take a step forward, take risks, and confront the unknown. They were all given a similar item of clothing and we talked about what this had to do with the idea of a collective venture or a cooperative. It became clear that in a cooperative the idea is for everyone to win, but it was understood that every person earns for the result of her own work.

This small experience had a strong impact on the group. It served to make them aware of the need for individual impulses and actions in order to achieve collective gain. It was another one of the episodes that was always told when new members arrived.

The second moment (transmission of accumulated knowledge) started from the sixth week onwards, the women conquered an important community learning space. They started meeting without the facilitators present, which had never happened before. They brought the facilitator a summary of a group discussion they had had during the week, expressing the following desires, still with an individual connotation: they wanted the opportu- 
nity to get out of the house more, to learn new things and to earn their own money. The fact that the group was already meeting without the facilitator needing to intervene or schedule a time already displayed an own impulse and voice and the spontaneity and creativity that Moreno (1997) refers to, in the form of a new response to old and congealed situations.

The community leadership was able to maintain this meeting in between our weekly visits to the community. We then became concerned with passing on basic knowledge to the group leader about how to conduct the meetings, allowing the group and herself to warm-up, take in the environment, perform a game and share. Despite the difficulty the embroiderers' leader had with the question of scenes or games, she understood the importance of the warm-up and always asked the facilitators for ideas. The suggestions we gave for her were to warm up the group with everyday activities, but done creatively, such as embroidering as a group, which they rarely did, or talking about the states and families they came from, as they had complained that they were neighbors but didn't know each other well. Between the sixth and seventh meeting, the group leader had already succeeded, during the week, without our participation, in formulating the group's objectives in the following way, now directed at collective action: 1) valuing women's work; 2) fair income by means of a cooperative; 3) working in the neighborhood and developing it.

The third moment (construction of group identity) ocurred in the twelfth meeting The warm-up activity involved talking a little among themselves about their childhood and what each one's favorite games had been. A game suggestion was for the group to compose lyrics to put to melodies that they all knew. The group, divided into three teams, was asked to make parodies with lyrics saying how they felt about forming the cooperative. Drummond \& Souza (2008) explain that music as a form of expression makes it possible to creatively overcome difficulties and communicate feelings and perceptions about organizational work. He also states that humor is the simplest and often the only way of making group participants realize the seriousness of the content they are dealing with, through unexpected creativity. The result of this activity was better self-esteem, group integration, the construction of a common identity and a common objective. The group's spirit at this moment is revealed by these composed lyrics. All the songs had rhymes in the original. The rhymes have been sacrificed in order to preserve the meaning.

$$
\begin{gathered}
\text { It's time, it's time } \\
\text { It's time to cooperate } \\
\text { Get your scissors and your thread } \\
\text { And let's all get to work } \\
\text { Jump, go forward } \\
\text { You don't know what you will learn } \\
\text { Here at the cooperative } \\
\text { No one is left without knowing } \\
\text { Cooperate and cooperate oh oh oh } \\
\text { Cooperate and work oh oh oh } \\
\text { With our cooperative } \\
\text { We will all get there }
\end{gathered}
$$

Trust and love, humility and understanding

With more help and trust

We can build unity

\subsection{The Newly-Hired Government Employees}

In a two-day project concucted by a consulting company, sociodrama was used combined with Creative Problem Solving $\left(\mathrm{CPR}^{\circledR}\right.$ ) (Osborn, 1953) as action strategy. The initial objective was to align expectations and questions of newly-hired employees of a state administrative body linked to the Agriculture Office of a Brazilian state. The target audience was highly diversified. We had learnt from the body's board of directors that normally, in spite of the low salaries, the positions attracted everyone from people with doctorate degrees, who dreamed of being directly linked to that line of action, to others who simply sought the comfort of a stable job. This is one of the guarantees that public sector jobs offer in Brazil, where employees cannot be dismissed once they have been 
hired, except in serious cases.

Due to limited time and the size of the group, made up of 120 people, the consulting company proposed that the focus of the work should be dealing with questions linked to interpersonal relationships and teamwork with its various phases, experiencing the main difficulties of conducting group activities. The group was aware of our positions, where we were at the same time game facilitators and facilitators linked to an academic institution.

On the first day, the group was warmed up with a strategy that started with "I", then "I and the other" and then forming the "we". These activities are inspired by Buber's (1996) concepts and serve as a base for the sociodramatic technique of role inversion, that is, so that subsequently each person is better able to put himself in someone else's shoes. Firstly, each person must draw on a piece of paper a symbol that represents them, inspired by an element of nature. Then they must look for a colleague that they do not know yet and introduce themselves with the symbol, explaining why they chose that element. Then, in a large circle, people said only their name, their town and the symbol that represented the colleague they had worked with, along with a personal quality they had noticed in their colleague during the presentation.

This type of warm-up follows the affective line proposed by Sternberg and Garcia (2000) and serves for people to gradually adapt to the space and prepare themselves for the themes to be worked on. They must be completely differentiated from the so-called "ice-breakers" of group dynamics, because the sociodramatic facilitator pays attention to group themes, feelings and expressions from when the warm-up starts. He does not use the warm-up to distract the group, but rather he lets the group use the warm-up as a form of expression, giving the director-facilitator guidance about the paths to follow.

On the same day, the morning was used for situation diagnosis activities based on song compositions, as with the embroiderers. The difference was that in this case the objective was to assess the group on arrival, while in the other case the activity was done in the twelfth meeting. The group members were invited to talk about what they expected to find, which they had already heard from their more experienced colleagues or had even experienced in the field, as some of them were already working.

After a few minutes the groups were enjoying themselves and the songs expressed their doubts and yearnings; fear of finding broken vehicles, lack of resources, excessive bureaucracy, bosses used to old and unproductive ways of doing things. On the other hand, a huge desire to help the rural man, an awareness of the need to make him stay on small properties and for permanent development of cheap planting techniques and distribution forms, which would allow small producers to compete with large ones and escape the middlemen. Some examples of the songs composed, freely translated:

I can't be

Unemployed for another minute

I passed the test

Now I have a job

I love everything I do

But I've been thinking, my love

Because the pay is low

And on top of that, guys

There is other stuff

This month I have no gas to get around

I'm from (name of the body)

I have my programs to take care of

I can't stop

I'm from (name of the body)

I believe things are gonna change

I won't give up

Another example:

My big prize

Was passing this test

I studied all my life!

To live emotions 


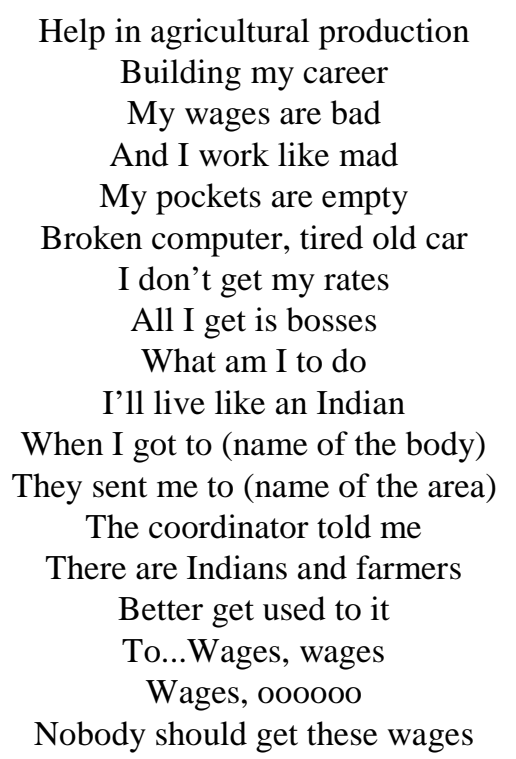

In that afternoon a physical warm-up was held, inspired by names of animals and birds from the regions the individuals came from. Then there began a "marathon” of teamwork games. The group was divided into three smaller groups of approximately 40 people and the consultants stayed in one place, each orienting one game, while the groups went from game to game. At the end of each game, which lasted about 20 minutes, the subgroup was invited to share how that activity related to their daily work life. The associations with teamwork, trust, communication problems and leadership arose naturally, obviously with different emphasis depending on the game. After all the subgroups had gone through all the games, the larger group was invited to sit in circles of 10 to 12 people and talk about their experiences. After that, each subgroup brought a summary of the conversation, in whatever form they wanted, to share with everyone. This way of working allows people to interact and trace parallels with their organizational reality and doesn't expose them, as in some forms of organizational theatre, because they only talk among themselves, in sociometric groups they have chosen.

The next day, to warm up the group, one of the coordinators did an activity in which he asked people, using sound equipment because of the large space, what towns they were from and what football teams they supported. Gradually he started showing team flags and playing their anthems, asking the fans to get together and sing. This was done in the reasonably familiar order of smallest fan base to largest fan base. In the end, when everyone was very animated, the music stopped and they were asked what team everyone supported when it played. There was a unanimous chorus: Brazil! A Brazilian flag appeared and the national anthem was played and sang by all. In an emotional moment, a young man spontaneously ran a kind of lap of honor with the unfurled flag, bringing Airton Senna, a Brazilian idol in F1 car racing, to mind. The group was then invited to reflect on how differences of religion, politics, sexual orientation, race, ethnicity and any other at certain moments can be left aside when a larger purpose or idea unites the group.

With everyone well warmed up, this second day served for the group to develop action plans for their arrival on the new job and what they hoped to do, after the previous day's reflections. This work was also coordinated so as to favor both diverging and parallel thought at first and only converging thought later, as is characteristic with $\mathrm{CPS}^{\circledR}$. The participants were asked to show, through intermediary objects, what they would change in the body they were working for, its most positive aspects and the aspects to be eliminated. Spontaneously, with this part of the work not being clearly directed, the group came up with a summary which said it wanted to talk about three main subjects: 1) planning; 2) interpersonal relations; and 3) communication.

They indicated as aspects to be transformed: adoption of a planning elaboration tool; establishment of an activity schedule in the units and involvement of all sectors in the projects in a participatory and decentralized manner. They indicated as positive aspects which should be permanently invested in: technical, professional and personal skills; qualifications with the institution's support; formation of a professional talent/skill bank; institutional marketing/image to highlight the institution's importance for the state, and unity and team spirit, with actions for integration of central, regional and rural bodies. And finally, they indicated as aspects to be eliminated: complacency (fighting against the cliché of civil servants as disinterested); lack of planning; the authoritarianism 
of older management and lack of action.

\subsection{The Employees of a Petrochemical Industry}

The third experience reported here happened during the six-month technical-operational training that is given to employees hired to operate in the petrochemical plants of a large national company. Although they are officially already hired and receiving salaries, they also undergo behavioral and experiential work every fortnight. In this type of work, action-research is in service of the hirer and the objective, clearly exposed to the group, is to assess the performance of each in aspects such as problem-solving creativity, teamwork, openness to change, leading and being led and capacity for concentration and situation analysis under pressure.

It was also clear for the group that these fortnightly meetings, a total of six during training, would not result in grades or failures but rather in a base for the preparation of future skills training. This is because those were the skills that team leaders in the petrochemical industry had indicated as fundamental for the people they led.

Below is one of the musical parodies written during one of the initial meetings, after the first visit to the refinery, also freely translated:

What is this unit, a sensation in Brazil

Of course it's (company's name), my brother

So many boilers and tubes in operation

It's oil in transformation

Come and work hard

Come and smile

Careful the unit doesn't explode...

(Company's name) is beautiful, I don't wanna leave

I'm going to stay here all my life

I'm really chilled, I'm at (company's name) and I'm in the operation

Tune in to this emotion

And your share in the profits will grow and grow...

It is important to remember that song composition by the groups is the scene or game itself, during which the group is at the same time author and director. After the songs are presented, and on this day there were four, the coordinator asks the group to talk about the process, how they felt, what it was like to work in a team and finally explores the theme of the songs, that is, reads and interprets them along with the group. It is also worth remembering that in sociodrama the director doesn't interpret the scenes, songs in this case, leaving this up to the group. That is, the group is free to bring up whatever themes they want, with whatever depth they like, without words being put in their mouth. The most that the coordinator, as facilitator, can allow himself is to ask what the group means with certain parts of the song. If the group says nothing, that it's unimportant, that's how it should be considered.

The work aimed to discover the main difficulties faced by these young people in their relationships with older employees. Particularly, aspects connected to safety equipment and when to follow routines established by the industry, which received much emphasis during training but little in practice, were discussed.

In the last training meeting, the group was asked to split up into three large groups and spend a whole morning creating and planning a samba school (the meeting was in Rio de Janeiro) that represented their main difficulties after six months of work. The main themes selected by each of the samba schools were difficulties with times and deadlines, safety measures and processes. These themes were brought up very creatively, being first experienced and then shared, as is characteristic of the sociodramatic method. After going through a playful and mobilizing experience, the group seemed confident to speak candidly about their difficulties, so as to elaborate action plans. Of course, for this to happen, a pact was made with the group that nothing that occurred during training would be revealed with individual names, and human resources would only hear about plans the groups had made and validated at the end of training.

\section{Analysis of Results}

As Drummond and Souza state (2008), it is in front of the group and face to face with its members that we can deepen planning and our own gaze. The facilitator, when dealing with an unknown reality, also needs to warm 
up, in order to open him or herself to new possibilities for seeing and understanding what state the group is in and what is easy or difficult for its members in their daily lives. This should be done without slogans and readymade materials, which often serve only to calm the nerves of the "director-educator-facilitator".

The above experiences have common aspects and differences. The use of the sociodramatic method as a form of expression unites them, but there are radical differences in conception, duration and intentionality that must be exposed. The use of sociodramatic strategy proves effective on both a higher, almost methodological, level, as with the embroiderers, and in more sociotechnical actions as with the other two reported cases. Here lies the danger of its effectiveness. Using a methodological concept as a central investigative procedure allows knowledge to be achieved; reducing it to a technique opens space for its ideological appropriation.

The learning process happened differently with each group. In the women's case there was growth and learning in the question of job and income generation. Some women reported that, with the elimination of middlemen in the embroidery chain and the resulting increase in household earnings, some of the husbands had stopped collecting refuse and living from odd jobs and instead had started doing embroidery at home, secretly or not. Some had become more skilled and productive than the women, as these were still performing their tasks as mothers and housewives. There was certainly learning in other areas of these people's lives, in relation to their husbands, children and in the dialogue with the community, but as this is a business administration project, these changes had to be left out of the final report. This clearly exposes the difference that exists within action-research work between field work and intervention work and what happens in both in terms of learning.

Freire (2005: p. 120) reminds us that at the start of an adult learning process: "[... the investigators must encourage those present so that the ones who want to participate directly in the investigation process as their aides come forward. This way, it will begin with a transparent dialogue among everyone]". The Brazilian educator also reminds us that there is only true dialogue when there is critical and compassionate thinking. The exchange of knowledge that occurred in the group led to the facilitator being better equipped to deal with the challenges of helping groups with minimum schooling to overcome the challenges of building organizations, even informal ones. It also led to a group that now sees the need for certain administrative concepts in even the simplest tasks. They realized that some ventures they had begun in the past in order to cross the poverty line, no matter how simple, had run into a kind of "administrative illiteracy", for example in the ignorance of what fixed and variable costs were, a relevant concept in individualism and in cooperativism, in socialism and in capitalism.

After a month of the intervention with the civil servants, there was a follow-up of what was being implemented out of the action plans. Although they said they were fighting against bureaucracy, after the meeting they were successfully developing a computerized planning tool for their actions, as well as making the tool and the information about the actions available on the body's network. They reported that the simple fact of being proactive made them feel more empowered and that many had left a space of complaint for a space of action. But no one can guarantee that the intervention didn't just motivate those people in their first months of work, reducing a feeling of impotence that will only reestablish itself afterwards.

As for the employees of the petrochemical plant, work with them is ongoing, with steps forward and backward regarding their confidence to implement changes. New cycles of intervention need to be permanently started, as is typical with action-research work. The industry is a 50-year-old plant, with a high risk operation and production pressure. Safety and production don't always go hand in hand, and production, profits and monthly bonuses do. These are dialectical and conflict questions that the group has permanently to solve with creative actions

\section{Final Thoughts}

Sociodrama focuses on liberating creativity. Therefore, deep reflection is needed when facilitators dedicate themselves to this methodology that enhances creativity and liberates human potential. This is because their interventions may be, as shown above, in service of maintaining the existing order or of radically changing the life of certain groups. It can be at the service of a better understanding and interpretation of reality by groups and facilitators, aiming to enrich relationships and increase the knowledge of both. It can also be in service of emancipatory questions and of the solution or enlargement of existing conflicts. Finally, it can serve the social change proposed by the radical humanist vision, a vision still under construction, but which is becoming urgent due to the aggravating socio-environmental questions facing global society. The situations here presented show that the same technique, used with different groups, is a creative way to intervene and work with groups. It can serve 
critical thinking and group bonding, as in the case of the embroiderers, can foster motivation, as in the case of the civil servants or help a group clarify values and define priorities, as in the case of the petrochemical industry employees.

The reflective interventionist facilitator knows that together with the building of knowledge he/she fosters the liberation of human potential as a part of the construction of social systems. Dogmatic postures can harm the intervention process during the transformation process of knowledge production. Reducing sociodrama to mere techniques can serve only to reproduce old ways of doing things. It is necessary to observe the relationships displayed in the daily life of organizations, as we use spontaneity and creativity in intervention and find out the way that domination operates in the field of practice. What this work aims to propose for further reflection is that creativity, if considered as a mind-opening and learning process, cannot be reduced to an investigation technique where the facilitator does not reflect about his/her own values and questions how ideas, knowledge and values are frozen again after his/her intervention. Otherwise the interventions may become unreflected hostages of ideology.

As action-research is based on the desire of the populations involved to act creatively to solve their problems, sociodrama seems to me to be well suited as an important ally. Well-prepared directors-facilitators who are familiar with certain tools such as composition of musical parodies, creation of newspapers with images and certain games, after some time are able to give groups fairly rigorous support in manifesting themselves and communicating their plans.

To this can be added other supports for a modern formation in sociodrama, such as the concept of roles (role playing, role creating) and the traditional tools of psycodrama (double, mirror, role reversal etc.). Again, those concepts have nothing to do with enactments or scenes in the sense of organizational theatre, theatre of the oppressed or any other form of individual exposure. They can be practiced with games or drawings, puppet theatre, storytelling, talking about films, etc. Insistence on theatrical scenes in companies, communities and in an organizational environment in general can be damaging to the promotion of sociodrama as an action strategy, since according to our experience it takes a certain ammount of time for a group to be ready to work with enactments and theatrical scenes on stage strictu sensu.

The use of sociodrama certainly has limitations and flaws. It works better with some groups than with others, in some group moments than in others. There are no indiscriminate possibilities for generalization. It requires specific preparation and qualification on behalf of the sociodramatic director-facilitator, as well as extreme sensibility, ethics and respect on behalf of the facilitator for the group and the content that is revealed.

Used without prejudice, sociodrama can be an extremely valuable strategy for groups to construct their own plans, involving people in a good-humored and creative way with the intervention and action process and making them committed to the results. In the organization of popular groups, sociodrama has, since the time of its founders, been proving itself as a tool that helps groups to unite, discover common interests and strengths, and mobilize to reach their ideals.

When sociodrama serves an organization's strategic interests, it is an important tool for mediation between management goals and the practical views of group members affected by these decisions. Action plans that come from this type of work, when they are implemented, can reflect positively on the results of organizations. This could be a theme for future empirical studies based on action-research work.

\section{References}

Aguiar, M. (2006). The Theatre of Spontaneity and Psycodrama Psychotherapy. In: Z. Figush (Ed.), Sambadrama: The Arena of Brazilian Psycodrama (pp. 141-155). London and Philadelphia: Jessica Kingsley Publishers.

Blatner, A. (2005). Perspectives on Moreno, Psychodrama, and Creativity. Journal of Creativity in Mental Health, 1, 111121. http://dx.doi.org/10.1300/J456v01n02_13

Blatner, A. (2006). Enacting the New Academy: Sociodrama as a Powerful Tool in Higher Education. ReVision: A Journal of Consciousness \& Transformation, 29, 30-35. http://www.blatner.com/adam/level2/blatnerefs.html

Buber, M. (1996). I and Thou. New York: Touchstone.

Drummond, J., \& Souza, A. C. (2008). Sociodrama nas organizações. São Paulo: Agora.

Holmes, P., Karp, M., \& Watson, P. (2004). Psicodrama após Moreno. São Paulo: Ágora.

Kaufmann, A. (1992). Teatro Pedagógico: Bastidores da iniciação médica. São Paulo: Ágora.

Lewin, K. (1970). Problemas de dinâmica de grupo. São Paulo: Cultrix. 
Marra, M. M. (2006). Práticas comunitárias: A natureza sociocultural e política do sociodrama. Revista Brasileira de Psicodrama, 14, 91-104.

Meisiek, S. (2004). Which Catharsis Do They Mean? Aristotle, Moreno, Boal and Organization Theatre. Organization Studies, 25, 797-816. http://dx.doi.org/10.1177/0170840604042415

Moreno, J. L. (1997). Psicodrama. São Paulo: Editora Cultrix.

Moreno, J. L. (1992). Quem Sobreviverá? Fundamentos da Sociometria, Psicoterapia de Grupo e Sociodrama. Goiânia: Dimensão Editora.

Osborn, A. (1953). Applied Imagination: Principles and Procedures of Creative Problem Solving. New York, NY: Charles Scribner's Sons.

Rodrigues, R. (2008). Quadros de referências para intervenções grupais psicosociodramáticas. Revista Brasileira de Psicodrama, 16, 75-92.

Rojas-Bermudez, J. G. (1983). Handpuppen als Intermediar-Objekte in der Behandlung von Psychotiker. Munich: Pfeiffer.

Sternberg, P., \& Garcia, A. (2000). Sociodrama: Who's in Your Shoes. Westport, CT: Praeger.

Yozo, R. Y. (1996). 100 Jogos para Grupos. Uma abordagem psicodramática para empresas escolas e clínicas. São Paulo: Agora.

Zanardini, A. C., \& Di Lascio, R. (2004). Psicodrama Organizacional: É possível ser espontâneo ou completo em busca de trabalho? Revista Eletrônica de Psicologia, 4, 1-9. 
Scientific Research Publishing (SCIRP) is one of the largest Open Access journal publishers. It is currently publishing more than 200 open access, online, peer-reviewed journals covering a wide range of academic disciplines. SCIRP serves the worldwide academic communities and contributes to the progress and application of science with its publication.

Other selected journals from SCIRP are listed as below. Submit your manuscript to us via either submit@scirp.org or Online Submission Portal.
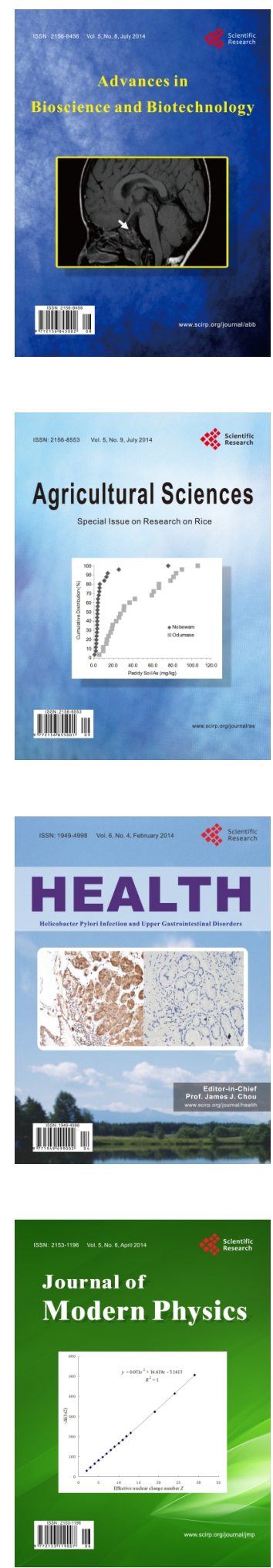
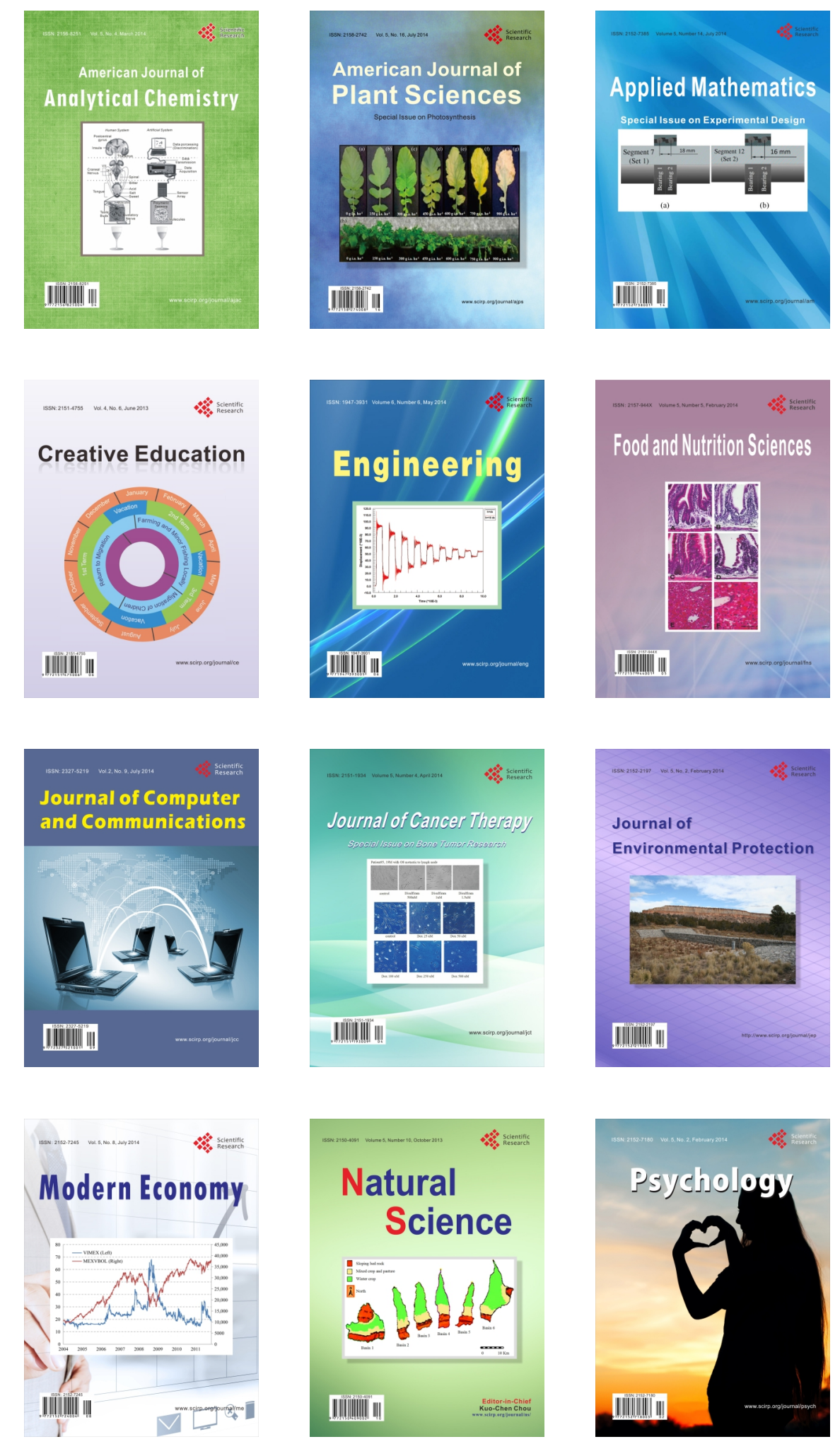